\title{
Kalan kron miktarının ve iki farklı fiber-post sistemlerinin endodontik tedavili dişlerin kırılma dayanımları üzerine etkisi
}

\author{
Hakkı Çelebi ${ }^{1}$, Arslan Terlemez $^{2}$, Emine Begüm Büyükerkmen ${ }^{1}$, Nimet Ünlü ${ }^{3}$, Emre Korkut ${ }^{4}$ \\ Selcuk Dent J, 2016; 3: 120-127 \\ Basvuru Tarihi: 06 Aralık 2016 \\ Yayına Kabul Tarihi: 06 Ocak 2017
}

\begin{abstract}
öz
Kalan kron miktarının ve iki farklı fiber-post sistemlerinin endodontik tedavili dişlerin kırılma dayanımları üzerine etkisi
\end{abstract}

Amaç: Bu in-vitro çalışmanın amacı iki farklı cam fiber-post sistemiyle restore edilen endodontik tedavi görmüş mandibular premolar dişlerde $2 \mathrm{~mm}$ yüksekliğinde kron varlığının ya da yokluğunun, dişlerin kırılma dayanımına etkisini araştırmaktır.

Gereç ve Yöntemler: Endodontik tedavi görmüş 56 adet yen çekilmiş tek köklü insan premolar dişi rastgele 2 gruba ayrıldı. Bir grupta dişler mine-sement birleşim yerinden kesildi. Diğer grup mine-sement birleşiminin $2 \mathrm{~mm}$ yukarısından kesildi. Gruplar iki alt gruba ayrıldı. GC ve Glassix olmak üzere iki farklı cam fiber post sitemi kök kanallarına simante edildi $(n=14)$. Simantasyon ișlemi çift așamalı polimerize olan rezin siman (Panavia SA Cement Plus Automix , Kuraray Noritake Dental Inc., Japonya) ile gerçekleştirildi ve disslerin koronal kısmı kompozit rezin kor materyali (Estelite Posterior, Tokuyama Dental Corp., Tokyo, Japonya) ile restore edildi. Daha sonra dişlerin üst yapısı metal destekli seramik sistemle restore edildi. Her bir numune akrilik rezin içerisine gömüldü ve üniversal bir yükleme test cihazına monte edildi. Dişin uzun aksına $135^{\circ}$ derece açı ile $1 \mathrm{~mm} / \mathrm{dk}$ piston hızıyla kırık oluşuncaya kadar yük uygulandı. Kırık tipleri X20 büyütmeli ışık mikroskobu altında incelenerek, tamir edilebilir ve tamir edilemez olarak sınıflandırıldı. Elde edilen verilerin istatistiksel analizleri Two Way ANOVA ve Tukey HSD testleri vasitasıly gerçekleştirildi.

Bulgular: Endodontik tedavi görmüş dişlerin kırılma direnci üzerinde bu çalışmada kullanılan post sistemlerinin ve kron yüksekliklerinin önemli derecede etkilendiği görülmüştür $(p=0.000)$. En yüksek kırıma dayanımının Glassix cam fiber post uygulanan ve $2 \mathrm{~mm}$ kron varlığı olan grupta olduğu görülmüştür.

Sonuç: Her iki cam fiber post sistemi uygulamasında, $2 \mathrm{~mm}$ kron varlığının olması dişlerin kırılma dayanımını arttııcı etki ortaya koymuştur.

\section{ANAHTAR KELIMELER}

Basma dayanımı, cam fiber, post ve kor tekniği

\section{ABSTRACT \\ Effect of remaining crown amount and two different fiber post systems on the fracture resistance of endodontically treated teeth}

Background: The aim of this in-vitro study was to investigate the fracture resistance of endodontically treated mandibular premolar teeth restored with two different glass-fibre-post systems, in the presence or absence of $2 \mathrm{~mm}$ crown height.

Methods: 56 recently extracted single-rooted human premolar teeth were endodontically treated and randomly divided into 2 groups. In one group the teeth were cut from the mine-cementum joint. The other group was cut from $2 \mathrm{~mm}$ above the cementenamel junction. Groups were divided into two subgroups and two different fiber post systems were cemented in root canals; GC and Glassix glass fiber post systems $(n=14)$. Cementation of post systems was performed with dual-polymerizing resin luting agent (Panavia SA Cement Plus Automix , Kuraray Noritake Dental Inc., Japan) and coronal portion of the teeth were restored with composite resin core material (Estelite Posterior, Tokuyama Dental Corp., Tokyo, Japan). Then, the superstructure of the teeth was restored with metal-ceramic system. Each specimen was embedded in acrylic resin and then mounted in a universal loadtesting machine. A compressive load was applied at a 135-degree angle to the long axis of the tooth until fracture, at a crosshead speed of $1 \mathrm{~mm} / \mathrm{min}$. The fracture types were classified through X20 magnification light microscopy to repairable and unrepairable. The obtained data statistical analyses were performed by means of the Two Way ANOVA and Tukey HSD tests.

Results: It has been observed that the post systems used in this study and the height of the crowns were significantly affected on fracture resistance of endodontically treated teeth $(p=0.000)$. The highest fracture resistance has been shown at Group which applied Glassix Glass fiber post and presence of $2 \mathrm{~mm}$ crown height.

Conclusion: Both glass fiber post system applications, presence of $2 \mathrm{~mm}$ crown height have revealed the effect of increasing the fracture strength of teeth.

\section{KEYWORDS}

Compressive strength, glass fibers, post and core technique

\footnotetext{
${ }^{1}$ Necmettin Erbakan Üniversitesi Diş Hekimliği Fakültesi Protetik Diş Tedavisi Anabilim Dalı, Konya

2 Necmettin Erbakan Üniversitesi Diş Hekimliği Fakültesi Endodonti Anabilim Dalı, Konya

${ }^{3}$ Selçuk Üniversitesi Diş Hekimliği Fakültesi Restoratif Diş Tedavisi Anabilim Dalı, Konya

${ }^{4}$ Necmettin Erbakan Üniversitesi Diş Hekimliği Fakültesi Pedodonti Anabilim Dalı, Konya
} 
Klinisyenler için madde kaybı fazla olan kanal tedavili dişlerin restorasyonları her zaman bir sorun teşkil etmektedir (Dikbas ve ark. 2007). Koronalde diş yapısı kaybı büyük miktarda olan, endodontik olarak tedavi edilen dişler, final restorasyon için sıklıkla kök kanalına bir post yerleştirilmesini gerektirir (Mosharraf ve Haerian 2011, Upadhyaya ve ark. 2016). Endodontik tedavi geçirmiş bir dişin restoratif ve protetik tedavisi, kalan sağlıklı dokuların miktarına, uygulanan kor restorasyonunun prognozuna, restorasyonun genel olarak yapısal ve estetik kalitesiyle, klinik adaptasyonuna bağlıdır (Dikbas ve ark. 2007).

Endodontik olarak tedavi edilmiş dişlerin restorasyonunda farklı teknikler ve materyaller uygulanmıştır. Metal prefabrik ve döküm postlar diş hekimliğinde klinik olarak uzun yıllardır uygulanmaktadır. Yaygın olarak kullanılan metal rengindeki postların hem restorasyon altından yansıyarak estetik sorun oluşturması hem de kırılma dayanımının iyi olmaması nedeniyle aşırı harabiyet gösteren dişlerin onarımlarında yeni geliştirilen materyaller ve teknikler diş hekimlerine yeni çözüm alternatifleri sunmaktadır.

Son zamanlarda tedavi yöntemlerindeki gelişmelerle diş rengindeki post talebine karşılık, metal olmayan postlar üretilmeye başlanmıştır (Goracci ve Ferrari 2011). Aynı zamanda bu materyallerin dentinin elastisite modulüne yakın elastisite modulüne sahip olmaları, endodontik olarak tedavi edilmiş dişlerde yapılacak restorasyonların klinik başarısı üzerine olumlu etkileri bildirilmiştir (Ferrari ve ark. 2000, Abduljawad ve ark. 2016).

Fiber postların mekanik özellikleri anisotropik olarak adlandırılmaktadır (Purton ve Payne 1996). Bu da, postların farklı doğrultularda yüklendiklerinde farklı fiziksel özellikler göstermesidir. Bu özelliğe bağlı olarak postların yükleme altındaki elastisite modülü de değişmektedir. Fiber postların en önemli avantajlarından biri elastisite modülünün dentinin elastisite modülüne $(18,6 \mathrm{GPa})$ yakın olmasıdır. Fiber postlarla birlikte kompozit rezin siman ve kor materyali kullanılmasıyla homojen bir bütünlüğün sağlandığı düşünülmektedir, yani bu materyaller birlikte kullanıldıklarında güçlü bir monoblok sistem oluşturarak kırılma riskini en aza indirgemektedirler. Paslanmaz çeliğin elastisite modülünün dentinin 20 misli, titanyumun ise 10 misli olduğu düşünülürse elastisite modülü 6,8-10,8 GPa olan rezin simanların, 5,7-25 GPa olan kompozit rezinlerin, 16-40 GPa olan fiber postların dentine çok yakın değerler gösterdiği görülmektedir (Dean ve ark. 1998, Boschian ve ark. 2002, Kıvanç 2006).

Döküm postlar ile karşılaştırıldığında, fiber postlar laboratuvar adımını kaldırarak kanal tedavisi sonrası seans sayısını azaltmakta ve işlemi basitleştirmektedir. Ayrıca, fiber postları kaldırmak ultrasonik veya döner aletlerle postun ortasından delik açmak yoluyla yapıldığı için, nispeten kolaydır (Gesi ve ark. 2003, Frazer ve ark. 2008). Ayrıca, kuvars veya cam fiber postlar restore edilmiş dişin doğal görünümünü sağlamada en olumlu optik özellikleri sunar (Vichi ve ark. 2000).

Uygun post ve kor materyali seçimi, yapılacak olan restorasyonun başarısı için oldukça önemlidir. Postlar, intraoral kuvvetleri radiküler dentinden çevre dokulara eşit olarak dağıtmalı ve koronal diş yapısını oluşturan korun retansiyonunu sağlamalıdır (Monaco 2002). Klinik başarı için post seçimi yapılırken kök kırıklarına eğilimi olan post sistemlerinden kaçınılması gerektiği bildirilmektedir (Sorensen ve Engelman 1990). Birçok çalışma, kalan diş yapısının açılı postlarla restore edilmesinin katastrofik kök kırıklarına neden olduğunu göstermiştir (Sorensen ve Martinoff 1984a, Sorensen ve Engelman 1990, Burgess ve ark. 1992).

Kron marjininin üzerinde koronal yüzey etrafında döküm metal grubu yapılmasının kanal tedavili dişlerin kırıma direncini önemli ölçüde arttırdığı bildirilmiştir. Kanal tedavili dişlerin kırılma dayanımlarının artııııması gerektiğinde, 'Ferrule Etki' olarak bilinen bu prosedürün uygulanması birçok araştırıcı tarafından tavsiye edilmektedir (Sorensen ve Martinoff 1984b, King ve Setchell 1990, Martinez-Insua ve ark. 1998).

$\mathrm{Bu}$ çalışmada, metal seramik kronla restore edilen madde kaybına uğramış dişlerde; iki farklı cam fiber post sistemi ve iki farklı kron yüksekliğinin (kronsuz kök ve $2 \mathrm{~mm}$ kron varlığı) dişlerin kırılma dayanımına olan etkisinin araştırılması amaçlanmıştır. $\mathrm{Bu}$ in-vitro çalışmanın araştırma hipotezi aşağıdaki gibidir:

1. Mine-sement birleşiminin $2 \mathrm{~mm}$ üstündeki koronal yapının (ferrule) varlığı fiber postlarla restore edilen endodontik tedavili mandibular premolar dişlerin kırılma dayanımını etkileyecektir.

2. Kullanılan fiber post sistemleri mine-sement birleşim yerinin üstünde $2 \mathrm{~mm}$ kron varlığı olsun ya da olmasın, endodontik tedavili mandibular premolar dişlerin kırılma dayanımını etkileyecektir.

\section{GEREÇ VE YÖNTEM}

Bu çalışmada benzer yaş, boyut ve anatomik şekle sahip 56 adet yeni çekilmiş insan mandibular premolar diş, örneklerin hazırlanması için kullanıldı. Kökler üzerinde var olan diş taşları kretuar yardımı ile temizlendi. Kök yüzeyleri temizlenen dişler distile su içerisinde saklandı. Her bir dişin tek köklü olduğu ve kök yüzeyinde çatlak olup olmadığı bir ışık mikroskobu (Celestron 44308 Dijital Pro Mini El Mikroskobu, ABD) altında incelenerek sağlam köklere sahip olan dişler çalışmaya dahil edildi. Daha sonra dişler rastgele 2 
gruba ayrıldı. 1. Gruptaki örnekler mine-sement birleşim yerinden, 2. Gruptaki örneklerde mine-sement birleşim seviyesinin $2 \mathrm{~mm}$ üzerinden su soğutması altında elmas bir separe yardımıyla kesildi.

Daha sonra kök kanalları içerisine 15 numaralı K tipi (VDW Antaeos K-Files, Vdw GmbH, München, Almanya) endodontik eğe ile girilerek kanalların açık olduğu ve tek köklü diş olduğu kontrol edildi. Bu kriterlere uygun olmayan dişler yenileriyle değiştirildi.

Kök kanal preperasyonu esnasında tıkanıklık oluşmasının önüne geçmek ve irrigasyon işlemlerini kolaylaştırmak için 15 numaralı K tipi eğe ile apikale kadar ilerlenerek apikalden 0,5 $\mathrm{mm}$ dışarıya çıkıldı. Daha sonra dişler $10 \mathrm{ml} \% 5,25$ lik $\mathrm{NaOCl}$ (Imicryl, Konya, Türkiye) ile $1 \mathrm{ml} / \mathrm{dk}$ olacak şekilde irrigasyonu yapıldı.

Daha sonra örneklerin kök kanalları endodontik döner eğe sistemi (The ProTaper NiTi files, Dentsply Maillefer;. Ballaigues, İsviçre) ile genişletildi. Genişletme esnasında eğe ile çalışma aşamaları arasında irrigasyon solüsyonu olarak \%5,25 sodyum hipoklorit ve \%17 EDTA (Imicryl, Konya, Türkiye) kullanıldı. Son yıkama işlemleri için distile su kullanıldı.

Daha sonra dişler, kâğıt konlar (Protaper, ISO Color Paper points, Dentsply Maillefer, Ballaigues, VD, İsviçre) ile kurutularak dolum işlemi için hazırlandı.

Genişletilen 56 diş, döner eğe sistemi ile uyumlu olan gutta perka sistemleri (Protaper Gutta-Percha Points, Dentsply Maillefer, Ballaigues, VD, İsviçre) ve Ah plus (Dentsply, DeTrey, Birleşik Krallık) kanal dolgu patı kullanılarak dolduruldu. Fazla gutta perka kısımları Gutta-Cut (VDW, $\mathrm{GmBH}$, Münih, Almanya) cihazıile kesildi. Ardından koronal kısımdaki fazla kanal dolgu patı alkol yardımı ile uzaklaştırıldı ve kök kanal dolgusunun polimerizasyonun tamamlanması için 48 saat süre ile $37^{\circ} \mathrm{C}$ de, karanlık ve nemli bir ortamda inkübatör içerisinde ağız ortamını taklit edecek şekilde bekletildi.

Kanal dolguları tamamlanmış kronsuz kök ve 2 mm kron varlığı olarak iki gruba ayrılan örnekler içlerine iki farklı post sistemi yerleştirilmek üzere iki alt gruba ayrıldı $(n=14)$. Böylece toplamda 4 farklı grup oluşturuldu.

Grup 1: GC fiber post (GC Corporation, Tokyo, Japonya) ile restore edilen kronsuz dişler $(n=14)$.

Grup 2: Glassix glass fibre composite posts (Harald Nordin sa, Chailly/Montreux, İsviçre) ile restore edilen kronsuz dişler $(n=14)$.

Grup 3: GC fiber post (GC Corporation, Tokyo, Japonya) ile restore edilen $2 \mathrm{~mm}$ kronlu dişler $(n=14)$.

Grup 4: Glassix glass fibre composite posts (Harald Nordin sa, Chailly/Montreux, İsviçre) ile restore edilen $2 \mathrm{~mm}$ kronlu dişler $(n=14)$.
Her iki post sistemi için de post çapları 1,20 mm seçildi ve kendine ait olan dril sistemi ile apikalde standart $4 \mathrm{~mm}$ uzunluğunda kanal dolgusu kalacak şekilde eşit uzunlukta $(10 \mathrm{~mm})$ üretici firma talimatları doğrultusunda post boşluğu su soğutması altında hazırlandı. Post boşlukları distile su ile temizlendi ve kağıt konlar ile kurulandı. Daha sonra \%30 fosforik asit solüsyonu (Gluma, Dormagen, Almanya) ile 30 saniye asitlendi ve tekrar son kez yıkanıp, kurulandı. Hazırlanan post yuvalarına post sistemleri Dual-cure (light- and/or self-cure), radiopaque self-adhesive rezin siman (Panavia SA Cement Plus Automix, Kuraray Noritake Dental Inc., Japonya) kullanılarak simante edildi ve polimerizasyon işleminin başlaması için 10 saniye ışık kaynağı (Elipar S10 LED Curing Light, 3M ESPE, ABD) ile polimerize edildi. Taşan rezin simanlar bir sond yardımıyla temizlendi ve koronal kök yüzeyleri kor yapıdan önce tekrar asitlenip yıkanıp kurulandı. Daha sonra kompozit rezin kor materyali (Estelite Posterior, Tokuyama Dental Corp., Tokyo, Japonya) ve ışıkla sertleşen bir bonding sistemi (Clearfil SE Bond, Kuraray Noritake Dental Inc., Japonya) ile restore edildi.

Kor yapısı oluşturulan örneklere üzerine metal destekli seramik restorasyon yapılabilmesi için su soğutması altında gingival seviyede elmas frez (Lingchen, Guangzhou Lingchen Trading Co., Çin) yardımıyla chamfer basamaklı diş preparasyonu yapıldı. Örneklerin koronal boyu bukkal marjinden $7 \mathrm{~mm}$ yükseklikte olacak şekilde hazırlandı. Chamfer marjinler metalseramik restorasyonlar için kabul edilen (Walton 1999) bukkalde $1,5 \mathrm{~mm}$ ve palatinale doğru azalarak 0,5 $\mathrm{mm}$ genişlikte olacak şekilde hazırlandı. Tek aşamalı polivinilsiloksan ölçü materyali (Elite H-D, Type. 1, Zhermack, İtalya) kullanılarak prepare edilen dişlerin ölçüsü alındı.

Metal-seramik kronlar Duceralloy C (DeguDent GmbH Hanau-Wolfgang, Almanya) krom-kobalt porselen metal alaşımı ile uygun Ceramco 3 (Dentsply Ceramco, Burlington, NJ, Amerika) porselen seramik kullanılarak hazırlandı. Daha sonra metal-seramik kronlar dişlere bir self adeziv rezin siman (Rely-X U200, 3M ESPE, Seefeld, Almanya) kullanılarak üretici firma talimatları doğrultusunda simante edildi.

Dişler mine-sement sınırına kadar kimyasal olarak polimerize akrilik rezin (Imıcryl, Konya, Türkiye) ile $3 \mathrm{~cm}$ boyunda $2 \mathrm{~cm}$ çapında silindir plastik kalıplar içerisine gömüldü. Daha sonra dişler plastik kalıplardan çıkarıldı ve dişlerin akril bloklar içerisinde bir bütün olması sağlandı. Tüm 
dişler test uygulamasından önce 1 hafta distile suda bekletildi. Üniversal test cihazında test deneyini gerçekleştirebilmek için akrilik rezin blokların $135^{\circ}$ derece sabit durmasını sağlayan özel bir aparat tornada hazırlatıldı. Ağız ortamında dişler üzerine gelen dik ve oblik kuvvetleri taklit etmek için dişlere $135^{\circ}$ lik açıyla kuvvet uygulandı.

Örnekler çekme basma test cihazına (Devotrans DVT GP D NN, Devotrans Itd şti,Türkiye ) dikey özel uç dişlerin bukkal cusp tepesine gelecek şekilde sabitlendi ve kırık oluşuncaya kadar $1 \mathrm{~mm} / \mathrm{dk}$ hızda olacak şekilde test işlemi gerçekleştirildi (Resim 1). Elde edilen verilerden kuvvet noktası en yüksek olan veri ve oluşan kırık tipi her bir örnek için kayıt edildi. Daha sonra bu kırık X20 ışık mikroskobu (Celestron 44308 Dijital Pro Mini El Mikroskobu, ABD) altında incelenerek; tipleri tamir edilebilir kırık (metal-seramik restorasyonda desimantasyon, kron kırığı, kor kırığı, mine-sement birleşiminin $2 \mathrm{~mm}$ altındaki kırıklar) ve tamir edilemez kırık (mine-sement birleşiminin altında $2 \mathrm{~mm}$ den daha fazla olan kırıklar ve post, kor, kron ve vertikal kök kırıklarının kombinasyonu) olarak sınıflandırıldı (Fragou ve ark. 2012).

Çalışmada test edilen tüm gruplardan elde edilen verilerin istatistiksel analizi SPSS 20.0 (IBM Inc., Chicago, IL, USA) paket programı kullanılarak İki Yönlü Varyans Analizi ve Tukey HSD teste tabii tutuldu.

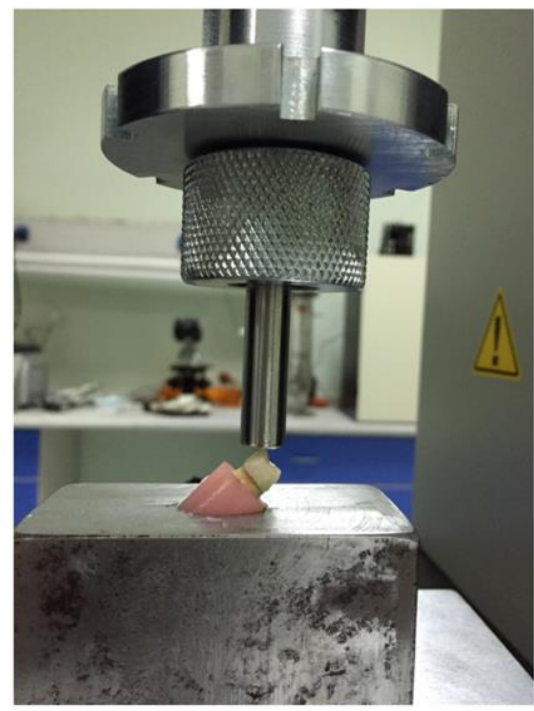

Resim 1.

Test cihazına sabitlenen örnek diş

\section{BULGULAR}

Universal test cihazı ile elde edilen verilere göre yapılan iki yönlü varyans analizi sonucunda farklı post grupları ve farklı kron yüksekliklerinin dişlerin bağlanma dayanımı üzerine etkisinin istatistiksel olarak anlamlı derecede olduğu görülmüştür $(p=0,000)$. Gruplara ait ortalama değerler ve standart sapmalar Newton ölçü birimi cinsinden Tablo 1'de ve Grafik1'de gösterilmiştir.

Kullanılan post sistemlerinin dişlerin kırılma dayanımına olan etkisi arasında istatistiksel olarak anlamlı fark bulunmuştur $(p=0.033)$.

Kron yüksekliğinin olmadığı (Grup 1 ve Grup 3) ve 2 mm kron varlığının olduğu (Grup 2 ve Grup 4) dişlerin kırılma dayanımına olan etkisi arasında istatistiksel olarak fark görülmüştür $(p=0,000)$.

Ayrıca her iki cam fiber post sistemi uygulamasında, $2 \mathrm{~mm}$ kron varlığının olması dişlerin kırılma dayanımını arttırıcı etki ortaya koymuştur. En yüksek kırılma dayanımının Glassix cam fiber post uygulanan ve $2 \mathrm{~mm}$ kron varlığı olan Grup 4 'te olduğu görülmüştür. Grup 1 ve Grup 3'teki kırılma dayanım değerleri birbirine yakın bulunmuştur.

\section{Tablo 1.}

\section{Grupların kırılma dayanımlarına ait ortalama ve standart sapma değerleri (Newton)}

\begin{tabular}{|lccc|}
\hline Gruplar & $\begin{array}{c}\text { Ortalama } \\
\text { Değer }\end{array}$ & $\begin{array}{c}\text { Standart } \\
\text { Sapma }\end{array}$ & $\begin{array}{c}\text { Örnek } \\
\text { Sayısı } \\
\text { (n) }\end{array}$ \\
\hline Grup 1 (Kronsuz GC fiber post ) & 465,58 & 112,74 & 14 \\
\hline Grup 2 (Kronlu GC fiber post ) & 731,33 & 249,94 & 14 \\
\hline Grup 3 (Kronsuz Glassix post) & 480,00 & 174,38 & 14 \\
\hline Grup 4 (Kronlu Glassix post) & $1.019,66$ & 348,83 & 14 \\
\hline
\end{tabular}

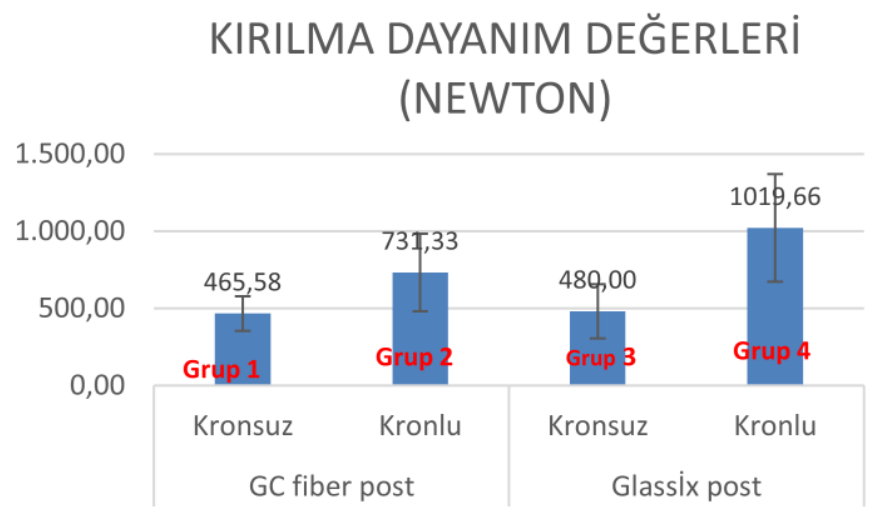

Grafik 1.

Grupların kırılma dayanımlarına ait ortalama ve standart sapmanın grafiksel gösterimi (Newton) 
Test sonucunda dişlerde oluşan kırık tipleri; ve diş sayıları Tablo 2'de gösterilmiştir.

Tablo 2.

\section{Gruplardaki kırık tiplerinin sınıflandırılması}

\begin{tabular}{|lcc|}
\hline & $\begin{array}{c}\text { TAMiR } \\
\text { EDiLEBiLiR }\end{array}$ & $\begin{array}{c}\text { TAMiR } \\
\text { EDiLEMEZ }\end{array}$ \\
\hline Grup 1 (Kronsuz GC fiber post) & 8 & 6 \\
\hline Grup 2 (Kronlu GC fiber post ) & 8 & 6 \\
\hline Grup 3 ( Kronsuz Glassix post ) & 12 & 2 \\
\hline Grup 4 (Kronlu Glassix post ) & 1 & 13 \\
\hline
\end{tabular}

Test sonucunda oluşan çeşitli kırık tipleri Resim2'de gösterilmiştir.

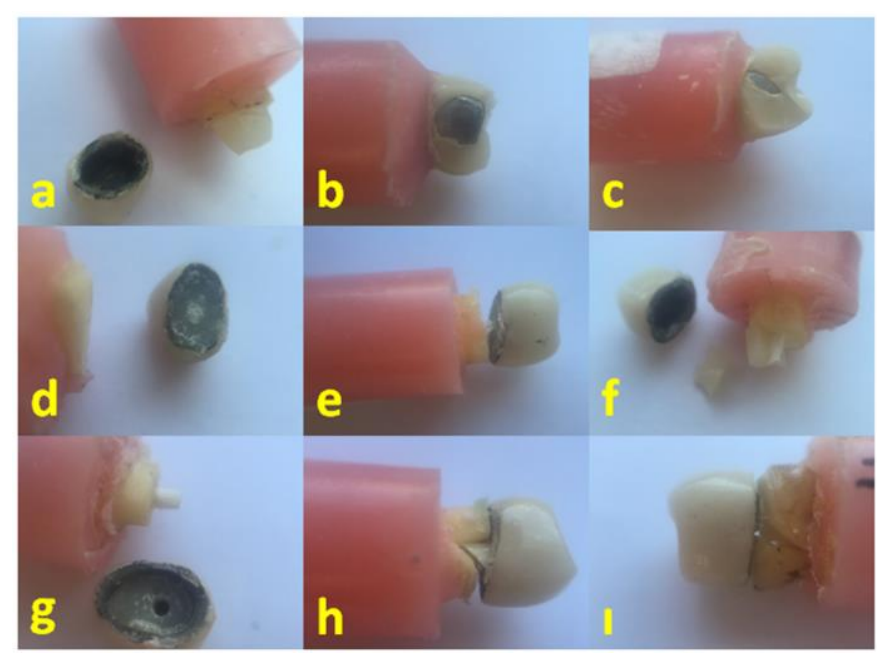

Resim 2.

Metal-seramik restorasyonda desimantasyon (a), metal-seramik restorasyondaki seramik kırı ğı (b,c), kronsuz dişlerdeki kor kırığı (d,e,f), kronlu dişteki kor kırığı (g), kök ve kor kırıklarının kombinasyonu $(\mathrm{h}, 1)$

Kırılma tipi analizlerinde kronsuz dişlere uygulanan her iki post sisteminin (Grup 1 ve Grup 3) kırılma tipleri benzer bulunmuştur. Kronlu dişlere uygulanan her iki post sistemlerinin kırılma tipleri birbirinden oldukça farklı bulunmuştur. Kronlu dişlere GC post sistemi uygulanan Grup 2'de tamir edilebilir kırık tipi oldukça fazla iken, yine kronlu dişlere uygulanan Glassix post sisteminde ise tamir edilemez kırık tipi daha fazla olduğu tespit edilmiştir.

\section{TARTIŞMA}

$\mathrm{Bu}$ çalışmada endodontik tedavili mandibular premolar dişlerin kırıma dayanımlarının kullanılan fiber post sistemlerinden ve mine-sement birleşiminin üzerinde $2 \mathrm{~mm}$ kron varlığının olup olmamasından etkilendiği görülmüştür. Bu bulgular araştırmanın hipotezini desteklemektedir.

Daha önceki bir çalışmada post uzunluğunun basma dayanıklılığı yönünden önemli olduğu ve klinik uygulamalarda kısa post materyallerinin daha az retansiyon oluşturdukları bildirilmiştir (Cheung 2005). 8, 9 ve 10 mm'lik post uzunluklarında maksimum makaslama stresleri kök-siman ara yüzünde oluşurken, 6, $7 \mathrm{~mm}$ 'lik post uzunluklarında ise streslerin apikal bölgede yoğunlaştığı bildirilmiştir (Gluskin ve ark. 1995, Toksavul ve ark. 2006). Çalışmamızda, kök içinde kalan post uzunluğu her iki post sistemi için de standart $10 \mathrm{~mm}$ olarak belirlenmiştir.

Farklı ferrule yüksekliklerinin $(0,5 \mathrm{~mm}$ ve $2 \mathrm{~mm})$ döküm post ve korlarla restore edilen dişlerin yükleme direncine etkisinin araştırıldığı bir çalışmada, en azından 1,5 $\mathrm{mm}$ bir ferrule yüksekliğinin uygun bir tedavi prognozu sağladığı sonucuna varılmıştır (Sorensen ve Engelman 1990). Bu çalışmada ise sıfır ferrule ve $2 \mathrm{~mm}$ ferrule yüksekliklerinin test edilmesi amaçlanmıştır.

Cam fiber postların rezin simanlarla bağlanma dayanımının oldukça yüksek olduğu, bükülme dayanımının dentine yakın olduğu ve stresleri geniş yüzey alanlarına dağıttıkları bildirilmiştir (Bateman ve ark. 2003, Toksavul ve ark. 2005). Bu çalışmada bu nedenle iki farklı cam fiber post sistemi rezin simanla simante edilip kırılma dayanımları karşılaştırıldı.

Amalgam, cam iyonomer simanlar, hibrit cam iyonomer simanlar ve kompozit rezinler kor yapımında kullanılan materyallerdir. Kor yapımında kullanılan materyallerin ağız içindeki çekme ve basma kuvvetlerini karşılayacak yeterli dirence sahip olması istenir (Naasan ve Watson 1998, Hayashi ve ark. 2006). Kompozit rezin materyalinin maniplasyonunun kolay olması ve sertleşme sürelerinin kısa olması klinik uygulamalarda kolaylık sağlamaktadır (Hudis ve Goldstein 1986, Nissan ve ark. 2001). Bu çalışmada kor materyali olarak kompozit rezin tercih edilmiştir.

Çalışmamızda her iki post sisteminin de en yüksek kırılma dayanımının 2mm' lik koronal yapıya sahip dişlerde elde edildiği görülmüştür. 
Fiberle güçlendirilmiş rezin postların döküm postlardan daha az vertikal kök kırığına neden olduğu ve döküm postların da fiber postlardan daha yüksek kırılma dayanımları gösterdiği bildirilmiştir (Zhou ve Wang 2013, A Alharbi ve ark. 2014). Fragou ve ark. (2012) endodontik tedavili kanin dişleri fiber postlarla restore ettikleri çalışmada $2 \mathrm{~mm}$ ' lik koronal yapının varlığının kırık tipini etkilemediğini ancak daha çok tamir edilebilir kırıklara neden olduğunu bildirmişlerdir. Bu çalışmada ise $2 \mathrm{~mm}$ 'lik koronal yapının olmasının farklı post sistemlerinin kırık tipini etkilediği görülmüştür. Kronlu ve kronsuz dişlere uygulanan GC fiber post sistemindeki tamir edilebilir ve tamir edilemez kırık tipleri birbirine benzer olarak gözlenmiştir. Diğer taraftan her iki kron boyundaki dişlere uygulanan Glassix fiber post sisteminde ise kronsuz dişlerde tamir edilebilir kırık tip çok yüksek sayıda iken kronlu dişlerde tamir edilemez kırık tipi oldukça fazla bulunmuştur. Glassix fiber post tipi kronsuz dişlerde GC fiber post sistemiyle benzer ve düşük kırılma dayanımına sahip olsa da kırık tipinin tamir edilebilir olması klinik dayanım açısından diğer post sisteminden daha avantajlı olabileceğini göstermektedir. Diğer taraftan Glassix fiber post sistemi $2 \mathrm{~mm}$ kron varlığı bulunan dişlerde GC fiber post sisteminden daha yüksek kırılma dayanımı gösterse de, en fazla tamir edilemez kırık tipi sergileyen grup (GC fiber post sisteminden \%50 oranında daha fazla) olmuştur. Bunun sebebi bu post sistemleri arsındaki elastisite modül farklılıkları ve kuvvetlere karşı olan dayanımlarındaki farkılık olabilir. $\mathrm{Bu}$ çalışmada kırılma testi sonuçları ve kırık tipleri değerlendirildiğinde daha yüksek kırılma dayanımının olduğu dişlerde kırık tiplerinin genellikle kor kırıklarıyla kombine kök kırıkları şeklinde olduğu gözlemlenmiştir (Resim2h, 2ı). Ayrıca hiçbir grupta mine-sement birleşiminin $2 \mathrm{~mm}$ altında oluşan tamir edilebilir kök kırığına rastlanmamıştır. Genellikle tamir edilebilir kırıklar kor kırığı, restorasyon kırığı ve post kırığı şeklinde olmuştur. Kırılma dayanımının yüksek olduğu dişlerde test sonucunda oluşan kırık tipi büyük çoğunlukla tamir edilemez kök kırığı şeklinde gözlemlenmiştir. Bu sonuç Glassix post sisteminin 2 mm'lik kronal yapı ihtiva eden dişlerde en yüksek kırılma dayanımı gösterirken, bu kırılma dayanımının artması tamir edilemez kırık tipinin de artmasına yol açmıştır.

Bütün gruplarda görülen kırıkların en çok kökün koronal üçlüsünde meydana geldiği ve bunun nedeninin kullanılan materyaller ve diş arasındaki elastik modülü farkından kaynaklandığını belirtilmiştir (Bolhuis ve ark. 2001).

Yetişkinlerde ön azı bölgesinde oluşan çiğneme kuvvetinin dikey bileşeninin ortalama $453 \mathrm{~N}$ ve yanal bileşeninin de $20 \mathrm{~N}$ olduğu bildirilmiştir (Brunski 2003). Bizim çalışmamızda 2 mm'lik koronal diş yapısının olduğu dişlerin ortalama kırılma dayanımları bu değerlerin daha üzerinde bulunmuştur ( Grup $2=731,33 \mathrm{~N}$ ve Grup $4=$ 1019,66 N). Kronsuz diş gruplarında ise bu değerler literatürdeki ön azı bölgesindeki çiğneme kuvveti değerlerine benzer çıkmıştır (Grup1 $=465,58 \mathrm{~N}$ ve Grup 3=480,00 N).

da Silva ve ark. (2010) endodontik tedavi yapılmış sığır anterior dişlerde yaptıkları çalışmada post, core, ferrule ve kron tiplerini karşılaştırmışlardır. Kor ve kron tipine bakılmaksızın, ferrule varlığının seramik kron grupları için bukkal gerginlik ve kırılma direncini önemli ölçüde etkilemediğini bildirmişlerdir.

\section{SONUÇ}

Bu çalışmanın sonuçları doğrultusunda;

Glassix post sisteminin $2 \mathrm{~mm}$ kronlu endodontik tedavili mandibular premolar dişlerde en yüksek kırılma dayanımı sergilediği fakat oluşan kırıkların tamir edilemez olduğu dikkati çekmektedir.

Glassix post sisteminden düşük olmakla birlikte GC fiber post sisteminin de $2 \mathrm{~mm}$ kronlu endodontik tedavili mandibular premolar dişlerde çiğneme kuvvetlerinden daha fazla bir kuvvete dayanma göstermesi veGlassix post sisteminin aksine oluşan kırıkların tamir edilebilir olması bu sistemin bir avantajıdır.

Bu bilgiler ışığında 2 mm' lik koronal diş dokusunun var olduğu ve fiber postlarla restore edilen endodontik tedavili mandibular premolar dişlerin ağız ortamındaki çiğneme kuvvetlerine daha dayanıklı olacağı düşünülmektedir. 


\section{KAYNAKLAR}

A Alharbi F, Nathanson D, Morgano SM, Baba NZ, 2014. Fracture resistance and failure mode of fatigued endodontically treated teeth restored with fiber-reinforced resin posts and metallic posts in vitro. Dent Traumatol,30, 317-325.

Abduljawad M, Samran A, Kadour J, Al-Afandi M, Ghazal M, Kern M, 2016. Effect of fiber posts on the fracture resistance of endodontically treated anterior teeth with cervical cavities: An in vitro study. J Prosthet Dent, 116, 80-84.

Bateman G, Ricketts D, Saunders W, 2003. Fibrebased post systems: a review. Br Dent J,195, 43-48.

Bolhuis HPB, De Gee AJ, Feilzer AJ, Davidson CL, 2001. Fracture strength of different core build-up designs. Am J Dent, 4, 286-290.

Boschian PB, Cavalli G, Bertani P, Gagliani M, 2002. Adhesive post-endodontic restorations with fiber posts: push-out tests and SEM observations. Dent Mater, 18, 596-602.

Brunski J, 2003. Biomechanics, In: Osseointegration in Dentistry, An Overview, Eds: Worthington P, Lang BR, Rubenstein JE, 2nd ed. Hanover Park, IL: Quintessence Publishing, Chicago, USA, pp; 49-84

Burgess JO, Summitt JB, Robbins JW, 1992. The resistance to tensile, compression, and torsional forces provided by four post systems. J Prosthet Dent, 68, 899-903.

Cheung W, 2005. A review of the management of endodontically treated teeth. Post, core and the final restoration. J Am Dent Assoc, 136, 611-619.

da Silva NR, Raposo LH, Versluis A, Fernandes-Neto AJ, Soares CJ, 2010. The effect of post, core, crown type, and ferrule presence on the biomechanical behavior of endodontically treated bovine anterior teeth. J Prosthet Dent, 104, 306-317.

Dean JP, Jeansonne BG, Sarkar N, 1998. In vitro evaluation of a carbon fiber post. J Endod, 24, 807810.

Dikbas I, Tanalp J, Ozel E, Koksal T, Ersoy M, 2007. Evaluation of the effect of different ferrule designs on the fracture resistance of endodontically treated maxillary central incisors incorporating fiber posts, composite cores and crown restorations. J Contemp Dent Pract, 8, 62-69.

Ferrari M, Vichi A, Garcia Godoy F, 2000. Clinical evaluation of fiber reinforced epoxy resin posts and cast posts and cores. Am J Dent, 13, 15-18.
Fragou T, Tortopidis D, Kontonasaki E, Evangelinaki E, loannidis $\mathrm{K}$, Petridis $\mathrm{H}$, Koidis $\mathrm{P}$, 2012. The effect of ferrule on the fracture mode of endodontically treated canines restored with fibre posts and metal-ceramic or all-ceramic crowns. J Dent, 40, 276-285.

Franco EB, Lins do Valle $A$, Pompéia Fraga de Almeida AL, Rubo JH, Pereira JR, 2014. Fracture resistance of endodontically treated teeth restored with glass fiber posts of different lengths. J Prosthet Dent, 111, 30-34.

Frazer RQ, Kovarik RE, Chance KB, Mitchell RJ, 2008. Removal time of fiber posts versus titanium posts. Am J Dent,21,175-178.

Gesi A, Magnolfi S, Goracci C, Ferrari M, 2003. Comparison of two techniques for removing fiber posts. J Endod, 29, 580-582.

Gluskin AH, Radke RA, Frost SL, Watanabe LG, 1995. The mandibular incisor: rethinking guidelines for post and core design. J Endod, 21, 33-37.

Goracci C, Ferrari M, 2011. Current perspectives on post systems: a literature review. Aust Dent J, 1, 7783.

Hayashi M, Takahashi Y, Imazato S, Ebisu S, 2006. Fracture resistance of pulpless teeth restored with post-cores and crowns. Dent Mater, 22, 477-485.

Hudis SI, Goldstein GR, 1986. Restoration of endodontically treated teeth: a review of the literature. J Prosthet Dent, 55, 33-38.

KIvanç BH, 2006. Endodontik tedavili dişlerde post uygulamaları. Atatürk Üniv. Diş Hek. Fak. Derg., 1, 18-23.

King PA, Setchell DJ, 1990. An in vitro evaluation of a prototype CFRC prefabricated post developed for the restoration of pulpless teeth. J Oral Rehabil, 17, 599-609.

Martinez-Insua A, da Silva L, Rilo B, Santana U, 1998. Comparison of the fracture resistances of pulpless teeth restored with a cast post and core or carbon-fiber post with a composite core. J Prosthet Dent, 80, 527-532.

Monaco C, 2002. Clinical studies, In: Fiber posts: clinical and laboratory data, Ferrari $M$, Scotti $R$, Masson Ed, Milano, Italy, 99-104.

Mosharraf R, Haerian A, 2011. Push-out bond strength of a fiber post system with two resin cements. Dent Res J (Isfahan), 8, 88-93. 
Naasan MA, Watson TF, 1998. Conventional glass ionomers as posterior restorations. A status report for the American Journal of Dentistry. Am J Dent, 11, 3645.

Nissan J, Dmitry Y, Assif D, 2001. The use of reinforced composite resin cement as compensation for reduced post length. J Prosthet Dent, 86, 304308.

Purton DG, Payne JA, 1996. Comparison of carbon fiber and stainless steel root canal post. Quintessence Int, 27, 93-97.

Sorensen JA, Engelman MJ, 1990. Effect of post adaptation on fracture resistance of endodontically treated teeth. J Prosthet Dent, 64, 419-424.

Sorensen JA, Engelman MJ, 1990. Effect of post adaptation on fracture resistance of endodontically treated teeth. J Prosthet Dent, 64, 419-424.

Sorensen JA, Martinoff JT, 1984a. Clinically significant factors in dowel design. J Prosthet Dent, 52, 28-35.

Sorensen JA, Martinoff JT, 1984b. Intracoronal reinforcement and coronal coverage: a study of endodontically treated teeth. J Prosthet Dent, 51, 780-784.

Toksavul S, Toman M, Uyulgan B, Schmage P, Nergiz I, 2005. Effect of luting agents and reconstruction techniques on the fracture resistance of prefabricated post systems. J Oral Rehabil, 32, 433-440.

Toksavul S, Zor M, Toman M, Gungor MA, Nergiz I, Artunc C, 2006. Analysis of dentinal stress distribution of maxillary central incisors subjected to various postand-core applications. Oper Dent, 31, 89-96.

Upadhyaya V, Bhargava A, Parkash $\mathrm{H}$, Chittaranjan B, Kumar V, 2016. A finite element study of teeth restored with post and core: Effect of design, material, and ferrule. Dent Res J (Isfahan), 13(3), 233238.

Vichi A, Ferrari M, Davidson CL, 2000. Influence of ceramic and cement thickness on the masking of various types of opaque posts. J Prosthet Dent, 83, 412-417.

Walton TR, 1999. A 10-year longitudinal study of fixed prosthodontics: clinical characteristics and outcome of single-unit metal-ceramic crowns. International Journal of Prosthodontics, 12, 519-526.

Zhou L, Wang Q, 2013. Comparison of fracture resistance between cast posts and fiber posts: a meta-analysis of literature. J Endod, 39,11-15.
Yazışma Adresi:

Yrd. Doç. Dr. Hakkı ÇELEBi

Necmettin Erbakan Üniversitesi

Diş Hekimliği Fakültesi Protetik Diş Tedavisi AD Karatay, Konya

Tel : +90332 2200026

Faks: +90332 2200045

GSM: +90 5552992873

E-mail: hcelebi@konya.edu.tr 